\title{
Simulation study on the effects of humidity reduction regulation and detection on indoor temperature comfort
}

\author{
Wen.-An. Wang ${ }^{1} *$, and Ssu.-Wei. Tung ${ }^{2}$ \\ ${ }^{1}$ Department of Architecture, Tamkang University, 25137 New Taipei City, Taiwan \\ ${ }^{2}$ Department of Architecture, Tamkang University, 25137 New Taipei City, Taiwan
}

\begin{abstract}
This study would discuss about the installation of indoor smart monitoring and control system and propose a feasible structure to establish a smart system for sensing and controlling the temperature and humidity inside the building. The sensor offers the capability of learning and automatically controlling the indoor temperature and humidity to automatically adjust the indoor heat environment.
\end{abstract}

\section{RESEARCH METHODS AND SIMULATION SETTING}

This study was focused on investigating and improving residential thermal environment. Temperature and humidity were manually adjusted, and computer simulation approach was employed to analyze the feasibilities of improving indoor thermal environment and comfort.

\subsection{Study Subject}

The study subject of this study was a low-rise residential building located in Tainan City of Taiwan. The space of the investigation was on the first floor with a dimension of $702 \mathrm{~cm}(\mathrm{~L})$ $\times 620 \mathrm{~cm}(\mathrm{~W}) \times 330 \mathrm{~cm}(\mathrm{H})$. Five indoor monitoring points were established.




Fig. 1. Floor plan of the study subject.

\subsection{Establishment of Local Meteorological Data}

Using the same indoor comfort environment, it was assumed that the meteorological parameters measured indoors at 12:00 noon were the basis for defining the indoor parameter boundary condition, and that the indoor air-conditioner was operating at steady state. Table 1 shows the conditions based on the meteorological data.

Table 1. Boundary Conditions of Meteorological Parameters.

\begin{tabular}{|c|c|}
\hline Attributes & parameter \\
\hline WIND & $\mathrm{V}=2.0(\mathrm{~m} / \mathrm{s})$ \\
\hline Humidity & $69 \%$ \\
\hline Scope of Calculation & Summer $\mathrm{T} 0=32^{\circ} \mathrm{C}$ \\
\hline
\end{tabular}

\subsection{Establishment of Local Meteorological Data}

$$
\begin{array}{|l}
\text { Temperature, } \\
40.00000 \\
38.75000 \\
37.50000 \\
36.25000 \\
35.00000 \\
33.75000 \\
32.50000 \\
31.25000 \\
30.00000 \\
28.75000 \\
27.50000 \\
26.25000 \\
25.00000 \\
23.75000 \\
22.50000 \\
21.25000 \\
20.00000
\end{array}
$$



(a)

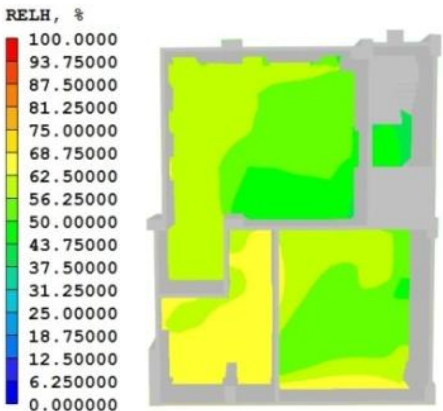

(b)

Fig. 2. (a) Temperature Field Simulation of the current situation ; (b) Humidity Field Simulation of the current situation.

The above analysis results indicate that the monitoring point measured maximum temperature of $32.92^{\circ} \mathrm{C}$ and minimum temperature of $29.81^{\circ} \mathrm{C}$ (at Monitoring Point 5). The overall indoor humidity level ranged between $50 \%$ and $70 \%$. Therefore, the overall indoor temperature was overly high, indicating an uncomfortable living environment.

Table 2. Simulation design.

\begin{tabular}{|c|c|}
\hline Module & Simulation Content \\
\hline Case1 & Adjust temperature to $32^{\circ} \mathrm{C}:$ Humidity $64 \%$ \\
\hline Case 2 & Adjust temperature to $32^{\circ} \mathrm{C}:$ Humidity $59 \%$ \\
\hline Case 3 & Adjust temperature to $32^{\circ} \mathrm{C}:$ Humidity $39 \%$ \\
\hline
\end{tabular}

\section{NUMERICAL SIMULATION AND ANALYSIS}


2.1 CASE 1 Adjust Temperature to $32^{\circ} \mathrm{C}$ : Humidity $64 \%$

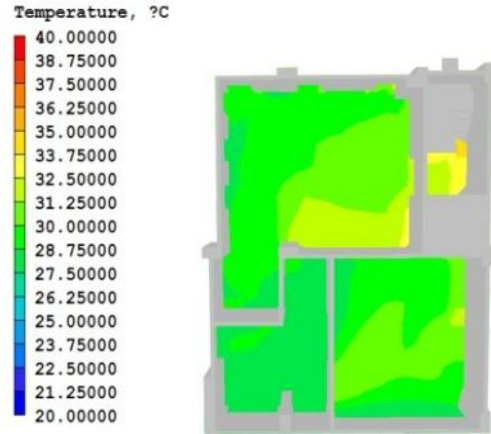

(a)



(b)

Fig. 3. Simulation of Case 1, Adjust temperature to $32^{\circ} \mathrm{C}$ : Humidity $64 \%$ : (a) Current Temperature Field of the current situation; (b) Improved Temperature Field Simulation of the current situation.

The above analysis results indicated that when humidity was reduced by $5 \%$, the cooling effect observed in Monitoring Points 1, 2, and 3 was weaker than that of the current situation. The overall average temperature measured at Monitoring Points 4 and 5 was reduced by $0.15-0.37^{\circ} \mathrm{C}$ compared with the current situation. Therefore, reducing humidity by $5 \%$ did not significantly improve the overall thermal environment.

\subsection{CASE 2 Adjust Temperature to $32^{\circ} \mathrm{C}$ : Humidity $59 \%$}

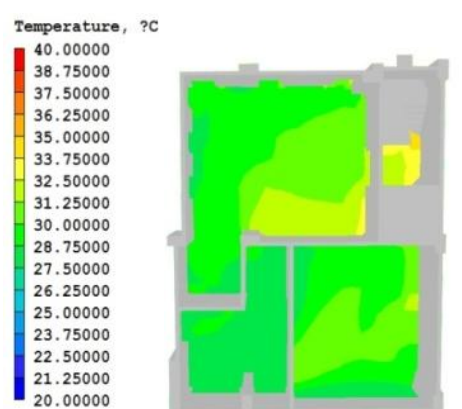

(a)



(b)

Fig. 4. Simulation of Case2, Adjust temperature to $32^{\circ} \mathrm{C}$ : Humidity 59\%: (a) Current Temperature Field of the current situation; (b) Improved Temperature Field Simulation of the current situation.

The analysis results showed that when humidity was reduced by $10 \%$, the cooling effect observed in Monitoring Point 3 showed approximately $0.13^{\circ} \mathrm{C}$ lower in temperature than that of the current situation, and the overall average temperature of Monitoring Point 4 was reduced by $0.47^{\circ} \mathrm{C}$, compared with the temperature of the current situation. Therefore, reducing humidity by $10 \%$ achieved optimal improvement of $0.13-0.47^{\circ} \mathrm{C}$ in overall thermal environment compared with the current situation.

\subsection{CASE 3 Adjust Temperature to $32^{\circ} \mathrm{C}$ : Humidity $39 \%$}




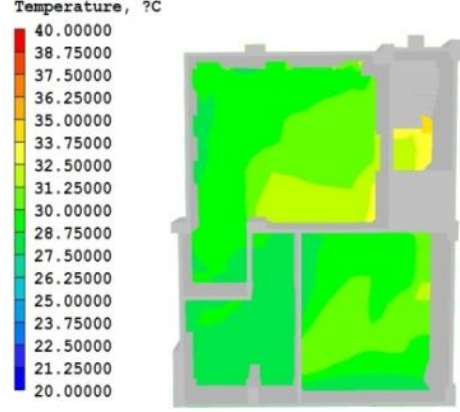

(a)

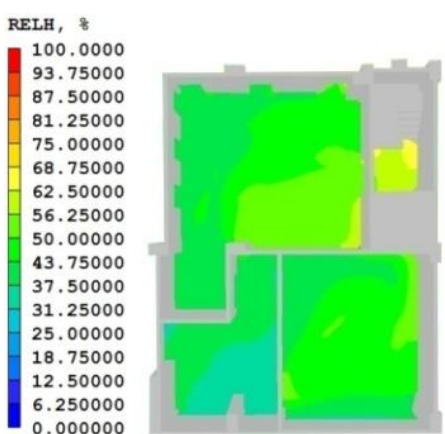

(b)

Fig. 5. Simulation of Case 3, Adjust temperature to $32^{\circ} \mathrm{C}$ : Humidity $39 \%$ : (a) Current Temperature Field of the current situation ; (b) Improved Temperature Field Simulation of the current situation.

The analysis results indicated that when humidity was reduced by $30 \%$, the cooling effect observed in Monitoring Points 1,2 , and 3 reflected $1{ }^{\circ} \mathrm{C}$ cooler in temperature than that of the current situation. The overall average temperature measured at Monitoring Points 4 and 5 was reduced by $1.22-1.38^{\circ} \mathrm{C}$ compared with the current situation. Therefore, reducing humidity by $30 \%$ significantly improved the overall thermal environment in comparison to the scenario in Cases 1 and 2.

\section{CONCLUSION}

The simulation results showed that when humidity and temperature were not adjusted, the optimal thermal module was indoor temperature of $32^{\circ} \mathrm{C}$, humidity of $39 \%$, and wind speed of $2.0 \mathrm{~m} / \mathrm{s}$. At this condition, significant cooling effect was observed. The overall average temperature decreased by $1{ }^{\circ} \mathrm{C}$ when humidity was reduced by $30 \%$. When cooling effect was achieved by adjusting temperature, the overall temperature cooled by roughly $4-5^{\circ} \mathrm{C}$; however, according to research, for every decrease in $1^{\circ} \mathrm{C}$ temperature, it increases $7-10 \%$ in electricity load, suggesting that from energy conservation point of view, although directly reducing temperature produced the best effect, but it also consumes the most amount of energy. because the locations of the monitoring points differed, the overall indoor environment can generate erroneous readings, causing some areas to reflect low comfort level. Subsequent studies could analyze the influence of distance and height of different indoor monitoring locations to calculate the mean values of the area, which provides input data for a smart control system to achieve temperature reduction and energy conservation.

\section{References}

1. Chou, P.C.; Chiang, C.M.; Li, Y.Y.; Lee, C.Y. \& Chang, K.F., Natural Ventilation Efficiency in Bedroomwith Central-Pivoting Window, Indoor + Built Environment , 2008, 17(2).

2. Huang, C.C. A Field Study on Thermal Comfort in University Classrooms. Thesis (PhM). Feng Chia University,2005.

3. Guang Dexin, Zhu Tingyao , Han Shijie. Theoretical model of drag coefficient of isolated tree, Sciental Silvae Sinicae, 2001: Vol.37, No.6.

4. O. HÄLSA. Comfort Climate Evaluation with Thermal Manikin Methods and Computer Simulation Models, Ph.D. Thesis, University of Gävle, Sweden, 2004. 